\title{
Efficacies of preoperative prism adaptation test and monocular occlusion for detecting the maximum angle of deviation in intermittent exotropia
}

Ryota Takada* (D), Fumiko Matsumoto, Akemi Wakayama, Takuya Numata, Fumi Tanabe, Kosuke Abe and Shunji Kusaka

\begin{abstract}
Background: The efficacies of prism adaptation test (PAT) and monocular occlusion (MO) and their optimal test durations to detect the maximum angles of deviation at near and distance in eyes with intermittent exotropia (IXT) were assessed and compared.

Methods: We retrospectively reviewed the medical records of 72 patients with IXT. All the patients had undergone the initial strabismus surgery between April 2015 and October 2018 and had been preoperatively tested by both PAT and MO performed on different days for 30 and 60 min. Near and distance deviations after 30 and 60 min of PAT and MO were compared to their baseline measurements obtained immediately after prism wear and before occlusion by alternate prism cover test. The near/distance measurements and required test duration to reveal the maximum deviation angle were also compared between PAT and MO.

Results: Compared with the baseline, the near deviation by PAT significantly increased after $30(P<0.05)$ and 60 $(P<0.01)$ minutes but not the distance deviation. However, the increase after 30 min was not significant. By MO, neither near nor distance deviation showed a significant difference from the baseline after 30 and 60 min. PAT showed a significantly larger near deviation than $\mathrm{MO}$ at 30 and 60 min, but a larger distance deviation by PAT was only observed at 30 min.
\end{abstract}

Conclusions: In patients with basic and convergence insufficiency types of IXT, a 30-minute PAT appears to be more effective than $\mathrm{MO}$ in revealing the maximum angle of deviation before strabismus surgery.

Keywords: Intermittent exotropia, Prism adaptation test, Monocular occlusion, Maximum angle of deviation

\section{Background}

Intermittent exotropia (IXT) is an outward deviation that breaks down spontaneously into a manifest exotropia; and it has two states, exotropia and exophoria. With the ultimate goal to preserve patient's good binocular vision and ability to maintain phoria, treatments for IXT

\footnotetext{
* Correspondence: taka_r@med.kindai.ac.jp

Department of Ophthalmology, Kindai University Faculty of Medicine, 377-2 Ohnohigashi, Osaka-Sayama, Osaka 589-8511, Japan
}

include strabismus surgery, prism therapy, and orthoptics [1]. Although strabismus surgery is the common treatment modality especially for patients with large deviations, postoperative recurrence remains challenging [2].

The performed surgical procedure [3], a young age at surgery [2], presence of suppression [1], and an underestimated angle of deviation [4] have been described as the factors for postoperative recurrence. The angle of

(c) The Author(s). 2021 Open Access This article is licensed under a Creative Commons Attribution 4.0 International License, which permits use, sharing, adaptation, distribution and reproduction in any medium or format, as long as you give appropriate credit to the original author(s) and the source, provide a link to the Creative Commons licence, and indicate if changes were made. The images or other third party material in this article are included in the article's Creative Commons licence, unless indicated otherwise in a credit line to the material. If material is not included in the article's Creative Commons licence and your intended use is not permitted by statutory regulation or exceeds the permitted use, you will need to obtain permission directly from the copyright holder. To view a copy of this licence, visit http://creativecommons.org/licenses/by/4.0/ The Creative Commons Public Domain Dedication waiver (http://creativecommons.org/publicdomain/zero/1.0/) applies to the data made available in this article, unless otherwise stated in a credit line to the data. 
deviation is usually measured using the alternate prism cover test (APCT). Pritchard [4] and Kushner [5] have emphasized the significance of detecting the maximum deviation, which determines the required amount of surgery and leads to the prevention of postoperative recurrence. However, revealing the true deviation will be difficult if fusion cannot be sufficiently removed during APCT. We have experienced IXT patients with difficulty to break fusion in the tested eye possibly due to the surrounding atmosphere during the test. Besides, fusion may not be sufficiently removed depending on the skill of the examiner. The reported influences of tenacious proximal fusion (TPF) [6] (Scobee phenomenon [7]) and tenacious distance fusion [5] can also prevent IXT patients from revealing the true deviation during APCT. Therefore, other than APCT, a method that can measure the maximum angle of deviation before strabismus surgery is clinically essential to the management of IXT.

The prism adaptation test (PAT) and monocular occlusion $(\mathrm{MO})$ are two effective methods to reveal the maximum angle of deviation $[8,9]$. PAT reveals the maximum deviation using a prism that neutralizes the deviation, and MO brings out the underlying deviation by eliminating fusion with occlusion. Good surgical outcomes using surgical doses based on the angles of deviations measured after PAT and MO have been reported in patients with IXT [10-12]. While some studies concluded that PAT and MO are comparable in revealing the maximum deviation [13, 14], others reported the superiority of PAT over MO for obtaining a larger deviation [15-18] and no consensus has been reached. The debatable optimal test durations (time for prism wear and total occlusion time) for both methods to detect the maximum deviation vary among researchers $[10,11,15$, $16,19-26]$, and this could be one of the reasons for the lack of consensus. Although a similar study has been conducted in esotropic patients [27], to our knowledge, no study has been conducted in IXT patients to investigate the optimal PAT and MO durations for revealing the maximum deviation.

This study aimed to compare the efficacies of preoperative PAT and $\mathrm{MO}$ for detecting the maximum angle of deviation within the same test duration (60 $\mathrm{min}$ ) and to determine the optimal test durations for both methods.

\section{Methods}

\section{Patients and the IXT types}

Subjects in this retrospective study were 72 patients (34 males; age range, 6 to 76 years, mean, $19.0 \pm 18.1$ years) with IXT, who had received the initial strabismus surgery at the Kindai University Hospital between April 2015 and October 2018. Of 72, 54 (75\%) were under the age of 19. All the subjects had corrected visual acuity of
1.0 (LogMAR equivalent 0.0 ) or better and had received preoperative PAT and MO for 30 and $60 \mathrm{~min}$. Exclusion criteria were patients with previous strabismus surgery, a vertical deviation angle of $\geq 5$ prism diopter (PD), and a dissociated vertical deviation.

The subjects' distance $(5 \mathrm{~m})$ and near $(30 \mathrm{~cm})$ deviations were measured by APCT with correction and their IXT types were classified as follows: basic type with a near/distance deviation difference of $<10 \mathrm{PD}$, convergence insufficiency type with a larger near deviation for more than $10 \mathrm{PD}$, and divergence excess type with a larger distance deviation for more than 10 PD. Of 72, 60 patients had basic IXT, 12 patients had convergence insufficiency type, and no patient had divergence excess type.

The protocol for this study was approved by the Ethics Committee of Kindai University Faculty of Medicine and adhered to the Declaration of Helsinki. Verbal informed consent was obtained from all the patients or parents.

\section{Test methods}

The patient's dominant eye was used for fixation in the test. To completely eliminate fusion, the examiner used a long cover when alternating the prisms to ensure that the eyes were not under binocular viewing. PAT used acrylic ophthalmic prisms (Gulden Ophthalmics, Pennsylvania, USA), and a prism with the distance deviation measured by APCT was applied over the patient's nondominant eye. The deviation angles immediately after prism wear (the baseline) and at 30 and $60 \mathrm{~min}$ were compared. In the MO test, the non-dominant eye was occluded, and the deviation angles before occlusion (the baseline) and 30 and $60 \mathrm{~min}$ after occlusion were compared. The measurements and the deviation changes after 30 and 60 min were also compared between PAT and MO. PAT and MO were performed on different days for each patient by the same examiner.

\section{Statistical analysis}

Statistical analysis used the Steel-Dwass method to compare the angles after 30 and 60 min with the baseline. The Wilcoxon signed-rank test was used to compare the deviation changes between PAT and MO. A probability value of $<0.05$ was considered statistically significant.

\section{Results}

Changes in the near and distance deviations after 30 and 60 min of PAT and MO

Table 1 shows the deviation angles measured at baseline and after 30 and $60 \mathrm{~min}$ of PAT and MO. The subjects' distance and near deviations (mean \pm standard deviation) by APCT were $26.4 \pm 6.6 \mathrm{PD}$ and $31.0 \pm 6.8 \mathrm{PD}$, respectively. Compared with the baseline, the near deviation (mean \pm SD) significantly increased after $30 \quad(3.5 \pm 3.9$ 
Table 1 The PAT and MO measurements of deviations

\begin{tabular}{lllll}
\hline & & Baseline & $\mathbf{3 0} \mathbf{~ m i n}$ & $\mathbf{6 0} \mathbf{~ m i n}$ \\
\hline PAT & near & $30.9 \pm 6.9$ & $34.4 \pm 6.7$ & $35.0 \pm 6.7$ \\
& distance & $26.4 \pm 6.6$ & $28.6 \pm 7.6$ & $29.0 \pm 7.6$ \\
MO & near & $31.0 \pm 6.8$ & $32.3 \pm 6.7$ & $32.8 \pm 6.8$ \\
& distance & $26.4 \pm 6.6$ & $27.8 \pm 7.0$ & $28.3 \pm 7.1$ \\
\hline
\end{tabular}

Values are presented as average \pm standard deviation (PD)

PD, $P<0.05)$ and $60 \mathrm{~min}(4.1 \pm 3.9 \mathrm{PD}, P<0.01)$ of PAT. However, the difference $(0.6 \pm 1.3 \mathrm{PD})$ between the measurements at 30 and $60 \mathrm{~min}$ was not significant. The distance deviations at 30 and 60 min did not significantly differ from the baseline. Compared to the baseline, neither near nor distance deviation significantly increased after 30 and $60 \mathrm{~min}$ of $\mathrm{MO}$.

The near deviations by PAT at 30 and $60 \mathrm{~min}$ were significantly larger than those by $\mathrm{MO}(P<0.01$, Wilcoxon signed-rank test; Fig. 1). PAT also showed a significantly larger distance deviation than $\mathrm{MO}$ at $30 \mathrm{~min}$ $(P<0.05$, Wilcoxon signed-rank test; Fig. 2$)$ but not at $60 \mathrm{~min}$.

\section{Changes of patients' IXT types}

After PAT, 9 (15\%) of the 60 patients with basic IXT converted to convergence insufficiency type. In these patients, the near/distance deviation differences by APCT and PAT were $5.6 \pm 1.0 \mathrm{PD}$ and $10.4 \pm 0.9 \mathrm{PD}$, respectively. The 12 patients with convergence insufficiency type before PAT remained the same after PAT.

\section{Discussion}

With a 60-minute test duration for PAT and MO, the angles of deviation measured after PAT were larger than those measured after MO. Furthermore, significant differences in near and distance deviations were only observed at 30 min and no significant difference between both methods was seen after $30 \mathrm{~min}$. These results demonstrated the efficacy of a 30-minute preoperative PAT and suggested that the stabilized fusion by prism adaptation (PA) could be more effective than the eliminated fusion by $\mathrm{MO}$ for revealing the maximum angle of deviation in IXT.

The current result showed that the angles of exodeviation measured after PAT were significantly larger than those after $\mathrm{MO}$ and this was in agreement with previous results [15-18]. The PAT and MO measurements may be comparable, but a larger angle of deviation after $\mathrm{MO}$ has not been reported previously. These results suggest that the preoperative use of PAT could be more effective than $\mathrm{MO}$ in revealing the maximum angle of deviation in IXT. A similar study in 19 patients with normosensoric esotropia concluded that it appears advisable to tailor surgery to patient's squint angle after PA [27]. In patients with IXT, motor fusion during PA is suppressed and sensory fusion stability is sustained in order for the displaced retinal image to be fused on the two foveae. Unlike MO that eliminates fusion with occlusion, PA brings sensory fusion into a stable status under binocular viewing and thus better elicits the underlying deviation.

The PAT measurements at near showed a greater increase than the measurements at distance in this study.

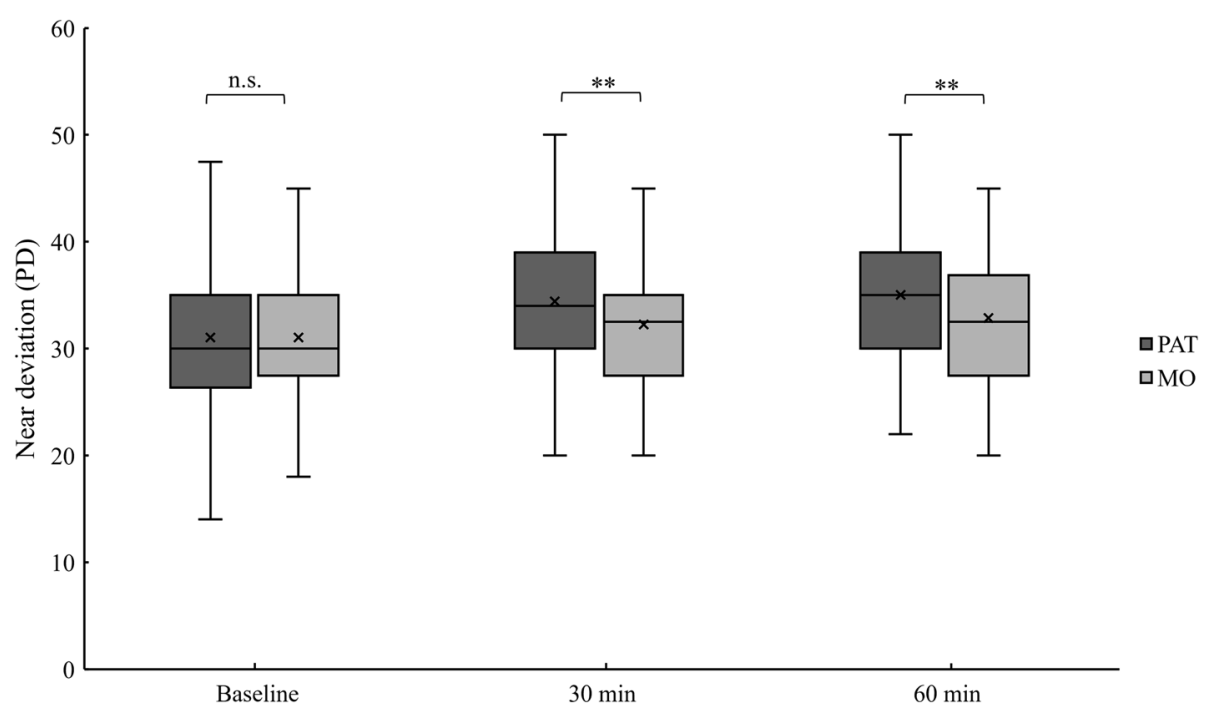

Fig. 1 Comparison of the near $(30 \mathrm{~cm})$ deviations by PAT and $\mathrm{MO}$ at the three time points. While the baseline APCT measurements did not significantly differ, the PAT deviations at 30 and 60 min were significantly larger than those by MO. Analysis used the Wilcoxon signed-rank test $\left({ }^{*} P<0.01\right.$; n.s.: not significant) 


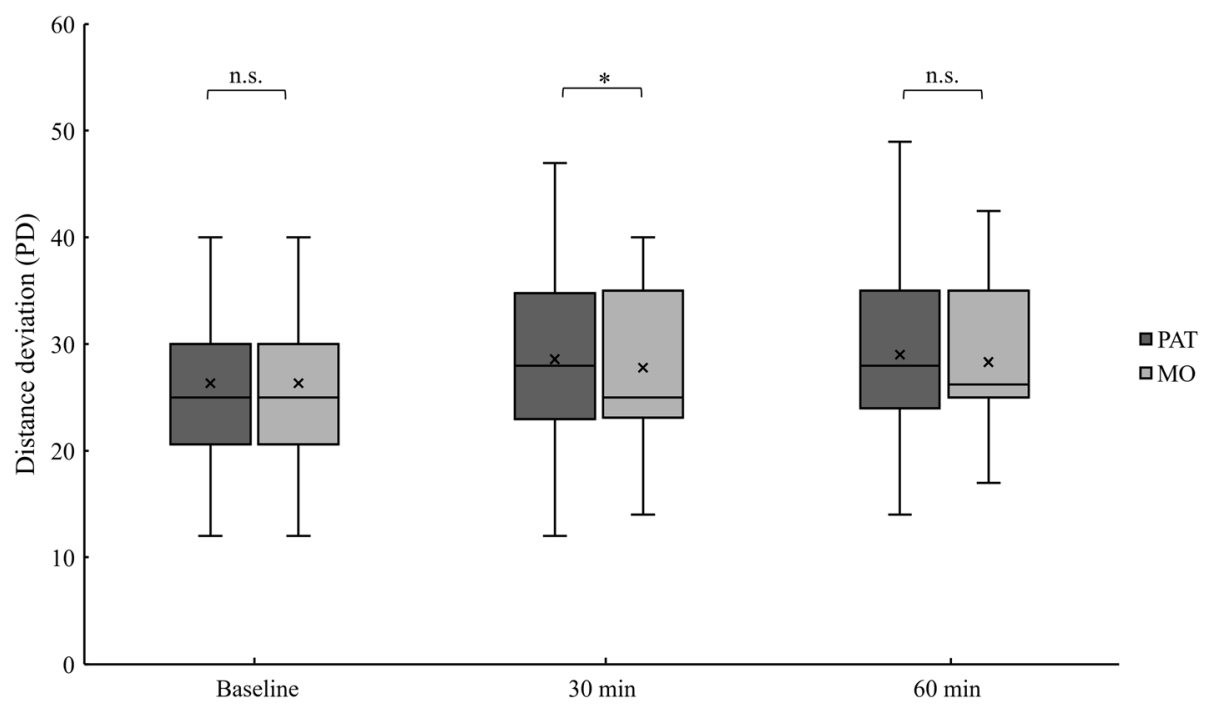

Fig. 2 Comparison of the distance $(5 \mathrm{~m})$ deviations by PAT and $\mathrm{MO}$ at the three time points. The distance deviations by PAT were also larger than those by MO, but the differences were not as distinct as the differences seen in the near deviation. Analysis used the Wilcoxon signed-rank test $\left({ }^{*} P<0.05\right.$; n.s.: not significant)

A previous study has reported a similar observation [19]. Furthermore, 9 patients with basic IXT before PAT converted to convergence insufficiency type after their near deviations increased. Vergence aftereffect (or slow vergence) is a temporary change in the eye position resulted from sustained fusional convergence. Reportedly, vergence aftereffect could mask the true near deviation in IXT and cause underestimated near deviation [26, 28$30]$. In addition, proximal convergence and vergence aftereffect also cause a higher accommodation convergence / accommodation (AC / A) ratio in IXT [31]. On the other hand, a smaller $\mathrm{AC} / \mathrm{A}$ ratio is observed after PAT [15]. With PAT showing the maximum angle of near deviation in this study, we therefore suspected that PA might have eliminated the influences of proximal convergence and vergence aftereffect and elicited the true underlying near deviation.

The distance and near deviations after 30 and $60 \mathrm{~min}$ of MO did not significantly differ from the baseline measurements by APCT, and they were all smaller than those by PAT. Hans and colleagues reported that the average maximum angles of deviation at distance and near on 3 or more examinations before $\mathrm{MO}$ are larger than those measured after 1-hour MO [32]. This suggests that 1-hour MO might not be able to reveal the same amount of deviation as 1-hour PAT. Furthermore, since MO and APCT shared the same mechanism that eliminated fusion by occlusion, the eliminated fusion might not be sufficient and this also explained why the maximum deviations by $\mathrm{MO}$ were smaller than those by PAT in this study.
Previously reported optimal PA time ranges from 30 min to 2 weeks $[10,11,15,17-19]$ and no consensus has been reached. A shorter PA time is always desirable especially in pediatric patients. In this study, near deviations after 30 and 60 min of PAT were significantly different from the baseline, but the increase after $30 \mathrm{~min}$ was not significant. In addition, no significant difference in near and distance deviations was observed after 30 min between PAT and MO. These results suggest the potential of a 30-minute PA for revealing the underlying deviation.

This study has some limitations. Because this study did not include patients with either divergence excess or pseudo-divergence excess IXT, the current results could only apply to patients with basic or convergence insufficiency type of IXT. The occlusion and PA durations were set for 30 and $60 \mathrm{~min}$ and thus, it was not clear whether and how the angle of deviation would further change beyond $60 \mathrm{~min}$. However, no subjects showed an increase of $\geq 5$ PD between 30 and $60 \mathrm{~min}$; and the measurements at 30 and $60 \mathrm{~min}$ did not significantly differ. We therefore considered that the deviation was unlikely to significantly increase after $60 \mathrm{~min}$. Because the AC/A ratios before and after $\mathrm{MO}$ and PAT were not available, the association between the $\mathrm{AC} / \mathrm{A}$ ratio and the increase in the near deviation could not be examined.

In conclusion, PAT is more useful than MO for preoperative detection of the maximum deviation in IXT. No significant changes in the near and distance deviations were observed after $30 \mathrm{~min}$ of PAT. Therefore, a 30-minute PAT has the potential to reveal the true 
underlying deviation in patients with basic and convergence insufficiency types of IXT.

\author{
Abbreviations \\ IXT: Intermittent exotropia; PAT: Prism adaptation test; MO: Monocular \\ occlusion; APCT: Alternate prism cover test; PD: Prism diopter; PA: Prism \\ adaptation; AC/A: Accommodation convergence / accommodation
}

\section{Acknowledgements}

The authors thank Reiyo Tahara for editorial support.

\section{Authors' contributions}

RT drafted and confirmed all versions of the manuscript. TN, FT, and KA collected data. FM interpretated the statistical analysis. AW drafted the manuscript and contributed to the data analysis and interpretation. SK supervised the study design and reviewed the final version of the manuscript. All authors read and approved the final manuscript.

\section{Funding}

There were no funding resources to declare for the manuscript preparation.

\section{Availability of data and materials}

The datasets used and analyzed in the current study are available from the corresponding author on reasonable request.

\section{Declarations}

\section{Ethics approval and consent to participate}

All the study procedures were approved by the Ethics Committee of Kindai University Faculty of Medicine and conformed to the Declaration of Helsinki. Verbal consent was obtained from all the patients or parents because this retrospective study contained no potentially identifying images, personal or clinical details of the participants.

\section{Consent for publication}

Not applicable.

\section{Competing interests}

The authors declare no competing interests or financial conflict of interests.

Received: 10 May 2021 Accepted: 4 August 2021

Published online: 21 August 2021

\section{References}

1. Von Noorden GK, Campos EC. Binocular vision and ocular motility. 4th ed. St. Louis: The C. V. Mosby Co; 1980. p. 330-6.

2. Matsuda K, Yokoyama T, Kawanami K. A study of effect of exotropia surgery -statistical analysis of the relationship between the age at surgery and the postoperative recurrence of exodeviation-. Folia Japonica Ophthalmol Clin. 1984;35:690-6.

3. Romano PE. World-wide surveys of current management of intermittent exotropia by MD strabologists. Binocul Vis Eye Muscle Surg Q. 1993;8:16776.

4. Pritchard C. Intermittent exotropia: how do they 'turn out'? Am Orthoptic J. 1993:43:60-6.

5. Kushner BJ. The distance angle to target in surgery for intermittent exotropia. Arch Ophthalmol. 1998;116:189-94.

6. Kushner BJ. Exotropic deviations: a functional classification and approach to treatment. Am Orthoptic J. 1988;38:81-93.

7. Kushner BJ. Tenacious proximal fusion: the scobee phenomenon. Am Orthoptic J. 2015;65:73-80.

8. Bergholz R, Salchow DJ. Intermittent exotropia. Klin Monatsbl Augenheilkd. 2015;232:1165-73.

9. Audren F. Intermittent exotropia. French J Ophthalmol. 2019;42:1007-19.

10. Ohtsuki $H$, Hasebe $S$, Okano M, Furuse T. Comparison of surgical results of responders and non-responders to the prism adaptation test in intermittent exotropia. Acta Ophthalmol Scand. 1997;75:528-31.

11. Dadeya S, Kamlesh, Naniwal S. Usefulness of the preoperative prism adaptation test in patients with intermittent exotropia. J Pediatr Ophthalmol Strabismus. 2003;40:85-9.
12. Ron A, Maria S. The use of the pre-op prism adaptation test (PAT) in surgery of exotropia. Am Orthoptic J. 1988:38:107-10.

13. Kushner B, Morton G. Distance/near differences in intermittent exotropia. Arch Ophthalmol. 1998;116:478-86.

14. Shippman S, Weintraub D, Cohen K, Weseley A. Prisms in pre-operative diagnosis of intermittent exotropia. Am Orthoptic J. 1988;38:101-6.

15. Kanaya M, Yuizumi M, Murai S, Imoto K. Influence of tenacious fusion inducing masked deviation in intermittent exotropia: analysis by monocular occlusion and prism adaptation test. J Japanese Assoc Strabismus Amblyopia. 2001;28:113-8.

16. Kanaya M, Yuizumi M, Kobayashi T. Influence of fusion inducing masked deviation in intermittent exotropia. Analysis by monocular occlusion and prism adaptation test - 2-. Japanese Rev Clin Ophthalmol. 2005;99:240-5.

17. Shimizu M, Sugasawa J, Utsumi T, Nakamura K, Sawa F, et al. Changes in eye position during prism wear in intermittent exotropia. comparison with occlusion test. Japanese Rev Clin Ophthalmol. 2000;94:760-2.

18. Shan Lin F-J, Li L-H, Wang. Comparative measurements of exodeviations in intermittent exotropia. Chinese J Ophthalmol. 2013;49(7):609-14.

19. Ohtsuki $H$, Hasebe $S$, Kono R, Yamane $T$, Fujiwara $H$, et al. Prism adaptation response is useful for predicting surgical outcome in selected types of intermittent exotropia. Am J Ophthalmol. 2001;131:117-22.

20. Scobee RG. The oculorotary muscles. 2nd ed. St. Louis: The C. V. Mosby Co; 1952. p. 172.

21. Von Noorden GK. Divergence excess and simulated divergence excess: diagnosis and surgical management. Doc Ophthalmol. 1969;26:719-28.

22. Burian M, Albert T. Evaluation of diagnostic methods for the classification of exodeviations. Am J Ophthalmol. 1971;71:34-41.

23. Scott WE. The value of diagnostic occlusion for intermittent exotropia. Am Orthoptic J. 1975;25:90-1.

24. Kushner B. Selective surgery for intermittent exotropia based on distance/ near differences. Arch Ophthalmol. 1998;116:324-8.

25. Shimizu M, Sugasawa J, Utsumi T, Nakamura K, Sawa F, et al. Evaluation of preoperative occlusion test for intermittent exotropia. Japanese Rev Clin Ophthalmol. 1999;93:902-5.

26. Cooper J, Medow N. Major review: intermittent exotropia basic and divergence excess type. Binocul Vis Eye Muscle Surg Q. 1993;8:185-216.

27. Schildwhchter-von Langenthal Annette, Kommerell Guntram, Klein Ulrike, Simonsz Huibert Jan. Preoperative prism adaptation test in normosensoric strabismus. Graefe's Arch Clin Exp Ophthalmol. 1989;227:206-8.

28. Ellerbrock V. Tonicity induced by fusional movements. Am J Optom Arch Am Acad Optom. 1950;27:8-20.

29. Schor CM, Ciuffreda KJ. Vergence eye movements: basic and clinical aspects. In: Schor CM, editor. Fixation disparity and vergence adaptation. Woburn: Butterworth; 1983. p. 465-516.

30. Sethi B. Vergence adaptation: A review. Doc Ophthalmol. 1986;63:247-63.

31. Schor CM, Ciuffreda KJ. Vergence eye movements: basic and clinical aspects. In: Kenyon CH, Ciuffreda KJ, editors. Accommodative vergence and accommodation in normal, amblyopes and strabismics. Woburn: Butterworth; 1983. p. 101-73.

32. Han JM, Yang HK, Hwang JM. Efficacy of diagnostic monocular occlusion in revealing the maximum angle of exodeviation. Br J Ophthalmol. 2014;98: $1570-4$

\section{Publisher's Note}

Springer Nature remains neutral with regard to jurisdictional claims in published maps and institutional affiliations.

Ready to submit your research? Choose BMC and benefit from:

- fast, convenient online submission

- thorough peer review by experienced researchers in your field

- rapid publication on acceptance

- support for research data, including large and complex data types

- gold Open Access which fosters wider collaboration and increased citations

- maximum visibility for your research: over $100 \mathrm{M}$ website views per year

At $\mathrm{BMC}$, research is always in progress.

Learn more biomedcentral.com/submission 